\title{
Innovation in Intercultural Contexts: Construction of Meaning from Reference Cultures
}

\author{
Jorge Miranda O. ${ }^{1}$, Carolina Villagra ${ }^{2} \&$ Segundo Sepùlveda ${ }^{2}$ \\ ${ }^{1}$ Facultad de Educaciò, Universidad Catòlica de Temuco, Temuco, Chile \\ ${ }^{2}$ Facultad de Educaciòn, Pedagogìa en Educaciòn General Bàsica, Universidad Catòlica de Temuco, Temuco, \\ Chile \\ Correspondence: Jorge Miranda O., Facultad de Educaciòn, Universidad Catòlica de Temuco, Temuco, Manuel \\ Montt 56, Chile. Tel: 56-45-220-5358. E-mail: jmiranda@uct.cl
}

Received: August 13, 2014 Accepted: October 11, 2014 Online Published: November 26, 2014

doi:10.5539/ies.v7n12p30 URL: http://dx.doi.org/10.5539/ies.v7n12p30

\begin{abstract}
This investigation was carried out in an attempt to respond to the issue of identification of codes for constructing meaning that yield to innovation. Based on the discourse of rural primary school teachers of la Araucania Region, Chile, we sought to expose key elements and codes that allow teachers to construct and/or re-elaborate meaning that may lead to change and innovation in educational contexts.

The investigation was conducted through a qualitative approach, and based on the teachers' discourse. The obtained data analysed focused on intersubjective shared meanings, which may be visualised through the teachers' representation of change and innovation. Specific attention was drawn upon the meaning construction for transformation in schools of la Araucania Region in rural contexts.

The obtained results reveal little relation between innovative discourses and the cultural context of reference. In addition, there is strong evidence of reduction of the innovative process on defined guidelines on behalf of the public school system.
\end{abstract}

Keywords: qualitative, discourse, teacher, school, innovation, interculturality, reference, rural

\section{Introduction}

As the case of many other countries, the educational system in Chile, has and is still undergoing through several reform processes. In the past twenty years the educational system has put a strain on the schools and teachers by demanding them to carry out changes in their practices and curriculum management, as well as going through innovation processes. However, hence the teachers, students and school administrators strong efforts to carry out the required demands, the crude reality is that the results obtained do not reach the expected goals. The question that emerges by analysing the previous situation is: why have there not been any transformations in the educational system if there have been economic and human resources allocated to improve the demands of the system in areas of curriculum management and continuous education? Apparently, change and innovation in the educational context continue to be an illusion. The lack of achievements increases the levels of inequity and inequality in the Chilean educational system and cause higher disengagement between the undergoing transformation processes and the school culture. The school culture constitutes a sociocultural scenario generating transformations that have little or nothing to do with the surroundings. This situation undergoes a crisis when the analysed space combines aspects of the rural location of the school and the high indigenous and rural population. The following research intends to organise some of the previous stated reflexions, emphasising on the teachers' discourse of meaning and innovation, as well as the change and correlation of these processes with the reference culture.

\subsection{Identifying the Problem}

Focused on the demands that put a strain on the educational system, the need to innovate is considered a matter of urgency. In this respect, the change posed on the school is associated with a set of quality indicators that need to be evidenced and guaranteed. This investigation intends to identify key aspects of the discourse of teachers in relation with meaning construction surrounding innovation. The proposition that underlines this investigation suggests that the official discourse prevails in the innovation proposals and therefore, in a certain sense, 
generates a denial process of the culture in both levels proposed (internal and external) which would eventually cause an innovation generation process disconnected to reality and impertinent of the cultural context that comprise it.

\section{Theoretical Framework}

The use of the concept innovation, seen from a scholar perspective, contains some clue characteristics. Its definition embodies a genuine intention to improve the quality of the educational processes and therefore, solve concrete problems (Perez, Diaz, \& Martinez, 2014), in this sense, innovation constitutes an articulated and related process, that intends to generate improvements, permanent and sustainable in time, with a focal point on the educational curricula. In consequence, innovation does not limit itself to technology (Marques, 2001).

In the analysis of educational innovation, literature incorporates some constituent attributes that allow to characterise the processes of change, for example planning as a central aspect of any transformation process in any school organisation. Therefore, it is considered that all planned action that intends to generate improvement in the different levels and aspects of the school organisation constitute an innovation, as well as, decision taking, degree of intention and systematicity. Several authors refer to these attributes in their reflections (Israel \& Fine, 2013; Holmes, Bourke, Preston, Shaw \& Smith, 2013; Dawson \& Andriopoulos, 2014; De la Cerna, 2003; Carbonell, 2006; Murillo, 2005, p. 2; Johnson, 2013; Lee, Williams, Shaw, \& Jie, 2014). Miranda (2013), the same authors state that the main objectives of the innovation process are to transform ideas, cultures, practices, in conclusion to look for a new form to understand and develop the educational program. In this aspect, Fullan (2002) incorporates to the definition an essential aspect of innovation, the author argues that, the natural space of innovation is the classroom, and therefore, we could also add that the context that constitutes it, is the reference culture.

Somehow the investigation accounts for some relatively common features respect to innovation as a process, and indicates that it does not constitute an isolated event. In this sense, the difference between an innovation and an innovative experience are made evident. In the former, emphasis is associated to the level and deepness of the innovative effect, therefore, we are in front of an innovation when there is a transformation in the ethos and the minds of the subjects of the organisation. In the latter, isolated actions are identified, lacking of orientation with respect to the greater project (Fullan, 2002). In another aspect, the intention of the action carried out and the connection that is produced with the improvement of the practices of the subject are revealed. Therefore, the idea of change as a concrete expression of innovation linked to the reference culture is deepened.

One important characteristic of innovation as a process is its relation with the curriculum and with the natural area of development: the classroom. It seems that all processes that do not enter the classroom, expressed as a transformation of practices linked to the curriculum, have no expectancy for succeeding, as they do not allow the subject to construct real meanings for innovation.

The latter constitutes a key element in the context of this work as the focus of the question was organised on the basis of the identification of keys for constructing meaning that lead to innovation. From the discourse of primary school teachers of rural schools of the Araucania Region, Chile we sought to expose key elements and codes that allow teachers to construct and/or re-elaborate meanings in order to achieve change and innovation from a reference culture expressed in the dynamics of the school. In this sense (Ghater \& Cirera, 2004) indicate that culture constitutes an aspect that precedes innovation and that more important is the system discourse and the ones of the theoretical of education, in consequence, innovation is the result of an individual construction, collective and interactive that is weakened if it is not in relation with culture and therefore, the dynamic of the relation between meaning and innovation and culture are developed from inside of the school as well as the environment that it holds.

In consequence, an innovation process would not be an action that could eventually be decreed nor systematically directed, (Ghater \& Cirera, 2004) state that it seems illusory to find hope in the role of the administration structure and in the role of the leader as a key aspect for the construction of meaning for innovation. In this sense the capacity to re elaborate and construct meaning from culture, marks the possibility that organisations may change or innovate, separating from adaptation of social systems and the supposed not discussed that persist in the word of life of the organisation systems that are colonised expression of the system. (Fullan, 2002), proposes that innovation is a process that implies communication patterns and construction of new forms of relation between the actors that conform the reality of the school, on the base of values, principals and common objective innovation that allow the construction of meaning. Therefore, the dimensional culture and the relation with it constitutes in itself a necessity and an emergency for the innovator. 


\section{Context}

This investigation was carried out in a group of 10 schools, located in the coastal area of the Araucania Region in the south of Chile. From a social and economic perspective the Araucania Region holds a series of indicators below the national average. According to official data of 2009 of the National Planning Ministry (MIDEPLAN), it embraces a low human development index that concentrates poverty at a high level. The region has a total of $7.6 \%$ homes defined as poor, and approximately $22 \%$ of the population considered to be in a situation of poverty. In school processes, the education average in the area reaches a $8.6 \%$. Furthermore, a $30 \%$ of the population integrates the Mapuche ethnic group. In general terms, the region is a territory with evident structural problems, where education assumes an important and crucial role for the development and growth of social expectancies. Therefore, innovation poses a necessity linked with progression of enormous groups of people.

One of the main characteristic of the schools used for investigative process, was that they were schools with just one teacher that took care of all of the students and who many times see themselves confronted to teach multigrade classes. Another group of these are schools only three or four teachers, which are mostly connected by land to rural zones with high presence of indigenous communities with whom they establish a direct relation and in some cases, assuming their own characteristics of an ethnic definition. However in other schools there was evidence of a certain level of breakup or disconnection with the reference culture that transforms the school in a foreign element to the dynamic community. With respecto to the teachers most of them showed vast experience in these type of schools. As many of the teachers interviewed in the study have dedicated their careers to working in these type of educational institutions, their biggest concerns are related to the risk of closing that rural schools confront due to the lack of enrolment. In general, they are teachers that present high levels of exhaustment in their work places, however they perceive themselves as valued by their communities.

\section{Methodology}

This is a qualitative research, Ruiz (2003), which intends to investigate a social phenomenon in order to provide answers to some concrete problems encountered in the study.

This research follows the lineaments of an interpretive methodological approach, since it looks for, as Geertz and Bixio (1992) state, interpreting observations that account for a social discourse: "rescue the words stated in previous occasions and fixed them in permanent terms".

In this study, the description and the interpretation of the representations of teachers, were recovered through the study of focus groups, which allowed gathering categories and determining the associations between them Salgado (2007).

For the research, a study case was created, referred to as an intensive, holistic description, and an analysis of a special entity, a phenomenon or a social unit (Perez, 2001) determined in this case, by rural school teachers of the Araucania Region.

The methodology of the investigation was carried out in three stages:

The first stage, related to the theoretical revision of innovation and change. It must be stated, that in this process the categories that led to the investigation were identified, as well as the categories that lead to the field work and that allow a further analysis of the data. The second stage of the process is connected to the realisation of focal groups with the teachers of the Araucania Region. Specifically, in their work with rural teachers in the coastal zone of the region, trying to account for the construction of their own meaning in front of innovation. The study was developed using a focal group technique that allowed to rescue the discourse of the participating subjects in a formal space of mutual trust. The sample of the teachers was constructed under the criteria of accessibility.

\section{Results}

In the aim of structuring the analysis of the texts obtained from the focus groups, two analysis categories were defined. The first of them referred to the construction of significance for innovation, and the second, innovation and culture relation. Both analysis categories, originate from the theoretical revision made.

Respect to the first category it must be indicated that the works carried out be Michael Fullan in the seventies (Fullan, 1972), note that one of the greatest problems of innovation and change are related to the existing scarcity between innovation and the user. In the year 1982 (Fullan, 1982) transforms the concept "user" to "meaning". The work of Fullan emphasis on the accent of the subject and how they intend to incorporate the idea of innovation and change in the extent that the individuals construct meaning for innovation. However, his work revelad the dimension of the individual phenomenon. On the other hand, Mónica Ghater (Ghater \& Cirera, 2004), states that the construction of meaning is defined as a key aspect which gives notice of the elements that allow 
the innovator to provide a higher value to the need of mobilisation in the search of newer options, than the status quo. Just like the author states, even though innovation is a contraction of individual meaning it gains higher sense and deepness when it is transformed in a collective and interactive action. In this sense, the construction is mobilised in different spheres of the task of the organisation (Ghater, 2004). Seen from the educational dimension, this meaning process inside of schools respond and mobilise the different levels of the organisation generated in the individuals and in the collective need to associate the transformation. In consequence, if the construction of meaning for change is a process which has basically an individual base, it collects higher strength and sense when it is the result of an action that implies a higher number of subjects.

Respect to the second category "innovation and culture relation" arises as the result of the revision of the work made by Csikszentmihalyi (1990) and also by Fullan and Stiegelbauer (1991). Both authors refer that the innovation is the result of a process where the relation of the innovation processes are sustained in the culture that provides sense to it and from which it recreates and invigorates. It is important to note that such relation constitutes a menacing element, as all the innovation poses in itself a reference frame in the internal (organisational culture) and the external (social culture of reference). In this sense all the process of innovation should converse in a permanent way with both cultural spaces, and should find in themselves their tasks and transformational purposes, and do it independently to the organisational culture and reference culture (i.e.: community, neighbourhood, district and region). Constituting the innovative actions expression in itself would not be considered as a deep innovation process that questions the organisation essence and the subjects and groups belonging to it. This point is perhaps a critic aspect in the relation between innovation and its results since the presence and/or absence of such aspect would condition the development of innovation. To this respect, the innovation culture implies suggesting the school as an open space, sensible and tolerant, to the others and to its own representations of the innovative work. So then, the innovation process accounts for a constant talk between the school and the community, Fullan (2002) states that "...if there is something we are certain about is that the change cannot be imposed" in this same sense, (Perez, Diaz, \& Martinez, 2014) state that an innovation that guarantees a certain level of effective output will be the one that is started, promoted and kept in the core of the school organisation and has the support of the whole school community, which shall perceive that the proposed innovation is needed.

Among the most important findings related to the first category "construction of significance for innovation" from the field work some elements that allow to characterise the construction of significance for change, were identified as the result of an external action. Discourses that give prevalence to the action of the system in its innovation processes prevail in them, in this sense the change is linked to technological support topics and documentation. It is interesting that respect to this point, teachers see as positive the support of the Ministry of Education they state "we have worked as a team [with the MINEDUC] and have got agreements" (GF1 inf 1) the work unifying element is basically the development of a series of actions linked to the Improvement Plans, the excess of work is accounted for as a participant variable and the force that the system work has over the changes in the school. In this sense, in some cases, innovation is linked with the compliance dimension, the expression "everything anybody asked me for, I try to comply" (GF1 inf 3) accounting for the mobilisation in front of innovation is the result of a reactive action and not the result of a personal or collective dynamic, considering the need of innovation. It is clear that the teacher's discourse emphasises that the construction of significance for innovation responds to a need from the external dynamics expressed in the necessities of the rural communities to resemble and integrate with the urban realities, which somehow, account for an invisibleness process of the difference and installation of a concept of competitiveness between rural and urban worlds, "there are changes, there has been a lot of changes in the rural schools concerning the children care since they do the same work as in the urban schools, there are scholarships where urban and rural schools compete at the same level" (GF1 inf2). Concerning this point, teachers say that change or innovation respond to a need linked with the enrolment, as if there is no "change", the number of enrolled students will decrease, "...we are surrounded by rural schools therefore, we have to take this approach. Otherwise, the urban schools will absorb our children" (GF1 Inf4)

Respect to the second category "relation innovation and culture", the findings account for a scarce relation and somehow an absence of that relation as it was stated in the previous point, the construction of significance of the subjects is not the result of a talk between the subjects, the community and the school itself. It is evident that the colonisation action of the system rises in this category and is linked to expressions such as "there are people who are demanding that their children have to learn English, that they have to know about computing, that they have to know about... Why? Because after that they are going to move to the city, to a larger school where they are taught English, and if the kid does not know English and is in...then they are demanding much more, because their mentality has changed. In fact, 28 years ago, mentality was completely different." (GF1 Inf1). In 
consequence, the aspect of the cultural environment reference seems to dilute or at least it is difficult to see. On the other hand, there is an excess of appreciation of external cultural elements and it is expressed in the absence of their own cultural elements, not giving importance to the country culture. In the same line the subjects state that "...Parents today are not the same as before. The fact that young people have changed, they have seen another world, in the past people did not travel much, today they have seen another world and see that there is a world out there and that people have become closer to the city, so they feel that to reach the city they have to be prepared, so then that has changed their mentality, the ages. Maybe if I had had the same guardians I would keep the same mentality but as they are younger people their mentality has been changing over the years." (GF1 Inf 4) The external element prevails, the school is not a changing agent but it is adapted to the external changes. There is not an important contribution of it as a cultural development space for the innovative process. The same it accounts for the superposition of urban culture over the ancient rural and country culture and that is expressed in the following statement "...Today the urban world is killing that part, it won't it survive" (GF1 INF2).

In this same category it calls the attention in the teacher's discourse that links the cultural topic setting linked to innovation form a perspective linked more to the most folkloric dimension of the cultural presence, the teachers say that they are the ones that celebrate the traditions and customs because despite that in their schools there is a $100 \%$ of Mapuche students, "...they are defined like this just because they have a Mapuche surname". In consequence, the transformation the school suffers or experiences is not the result of a dialogue with the referred culture but the result of a broken and occasional action.

\section{Conclusions}

The conclusions can be organised around the analysis of the proposed categories:

Respect to the first category, it is evident that from the discourse of the subjects, there is a clear prevalence of external forces in the construction of significances for innovation. In specific terms, colonising actions of the systems of the worlds of the subjects lives and the educational organisations represented by the school prevail. In this sense, the excessive valuation of the teachers respect to the action of MINEDUC and the predominance of the technical discourses derived from the official discourse, account for an installation process of the systemic logics over the discourse of the teachers themselves, stating in their discourse that the existence of the ministry proposals constitutes per se an innovative process and practice transforming. Somehow the construction of significance suffers a kind of cognitive de-personalisation since the action of the system over the action of the subjects themselves from their dimension of construction of significance is exaggerated and overvalued. When going back to the previous reflections, the innovative process is basically a group of innovative actions moving to a speed and consideration of the administrative management in turn, setting aside the need of constructing significance from the personal and collective construction itself in front of innovation. At this point the learning and practice communities installation constitute the first link in the improvement chain.

Respect to the second category, it is possible to conclude that the proposed innovation and desired by the teachers is the result of a social system request and is the reflection of a deep disassociation with the reference culture in the two proposed dimensions, the internal and external. Respect to the first one, the internal, it is evident that in the teachers' discourse they not only devalue the organisational culture but also the need of innovation is linked to the need to better respond to the established by the system and the urgent need of approving a reference culture, the urban. The teachers' discourses also account for the scarce or null correlation of innovation with the reference culture expressed in the discourse with the community and the construction of joined proposals. Innovation in this sense, considering the systemic character it has, appears as a colonising action of the official system and it is expressed with a disruptive tone which would not allow a dialogue with the knowledge installed in the community. In this way, innovation is the expression of the quality assumed by the teachers, and the school.

Referring to both categories a significative finding for this work must be given reference to, if all definitions originated from public policies, respect to the need of innovation as an improvement space, seen from the school perspective would be a vague discourse without sense. In the measure that they do not relate with their direct environment and with their one dynamic developed inside the organisation, leaving the discourse in a structural management plan that will not touch the daily practice of the teacher nor the relation of the clientele of the families that do not see the real participation paces in their community. Respect to all the defined transformations originated from the divine and packed form the systems structure, generating disconnected situations, impertinent and irrelevant with respect to innovation change which wishes to be carried out in sensitive contexts as the ones studies in this work. 


\section{References}

Carbonell, J. (2000). La aventura de innovar: El cambio en la escuela (Vol. 7): Ediciones Morata.

Csikszentmihalyi, M. (1990). Flow: The psychology of optimal experience. Nueva York: Harper Collins Publisher [ed. cast: Fluir (Flow): una psicología de la felicidad.Barcelona: Kairós, 1995].

Dawson, P., \& Andriopoulos, C. (2014). Managing change, creativity and innovation. Sage.

De la Cerna, C. R. A. G. (2003). Ense-anza virtual para la innovación universitaria: Narcea Ediciones.

Fullan, M. (1972). Overwiew of innovative process and the use. Interchange, 3, 1-46.

Fullan, M. (1982). The meaning of educational change. Nueva York: Teachers College Press.

Fullan, M. (2002). Las fuerzas del cambio (Vol. 5). Ediciones AKAL.

Fullan, M., \& Stiegelbauer, S. (1991). The new meaning of educational change. Nueva York: Teachers College Press

Gather,T. M., \& Cirera, J. V. (2004). Innovar en el seno de la institución escolar. EDITORIAL GRAO.

Geertz, C., \& Bixio, A. L. (1992). La interpretación de las culturas (Vol. 1): Gedisa Barcelona.

Holmes, K., Bourke, S., Preston, G., Shaw, K., \& Smith, M. (2013). Supporting innovation in teaching: What are the key contextual factors? International Journal of Quantitative Research in Education, 1(1), 85-102. http://dx.doi.org/10.1504/IJQRE.2013.055644

Israel, M. S., \& Fine, J. (2013). Moving outside the comfort zone: An innovative approach to principal preparation. Planning changing, 43(3/4), 294-308.

Johnson, M. (2013). Teachers as Agents of Change Within Indigenous Education Programs in Guatemala and Mexico. Comparative and International Education, 1, 153-170. http://dx.doi.org/10.1007/978-94-6209-218-1_9

Lee, A., Williams, R. D., Shaw, M. A., \& Jie, Y. (2014). First-year students' perspectives on intercultural learning. Teaching in Higher Education (ahead-of-print), 1-12.

López, C. M., \& Saborido, D. M. (2014). La gestión de proyectos de innovación educativa basados en el aprendizaje cooperativo: Análisis para su implementación. Revista Ibero-Americana de Estudos em Educação, 9(1).

López, C. P. (2001). Técnicas Estadísticas Con SPSS versión 10. Primera ed. España: Pearson.

Marqués, P. M. (2001). Algunas notas sobre el impacto de las TIC en la universidad. Educar, 28, 83-98.

Miranda, O. J. (2013). Factores que obstaculizan el cambio en profesores y directivos de liceos vulnerables en la región de la Araucanía. Educar, 49.

Murillo, J. (2007). Investigación Iberoamericana Sobre Eficacia Escolar (1st ed.). Colombia: Convenio Andrés Bello.

Pareja, J., \& Serrano, R. (2013). Rasgos fundamentales para que las innovaciones en educación sean exitosas: Algunas experiencias que lo corroboran.Etic@Net., 2(1), 324-356.

Pérez, Díaz, E., \& Martínez, A. (2014). Atrévete a innovar. Recetas para diseñar proyectos de innovación docente. La Rioja.

Ruiz, O. J. I. (2003). Técnicas de triangulación y control de calidad en la investigación socioeducativa. Bilbao: Ediciones Mensajero.

Salgado, L. A. C. (2007). Investigación cualitativa: Dise-os, evaluación del rigor metodológico y retos. Liberabit, 13(13), 71-78.

Sánchez, E. F., \& Flores, J. Y. (2014). 9. La formación docente y el desarrollo curricular como alternativas de innovación educativa. EDUCARE, 17(1).

Schauble, L., \& Glaser, R. (2013). Innovations in learning. New environments for education. Routledge (e.g. 2), 4. 


\section{Copyrights}

Copyright for this article is retained by the author(s), with first publication rights granted to the journal.

This is an open-access article distributed under the terms and conditions of the Creative Commons Attribution license (http://creativecommons.org/licenses/by/3.0/). 